\title{
PENGARUH GAYA KEPEMIMPINAN, DISIPLIN KERJA DAN KOMPENSASI KERJA TERHADAP KINERJA KARYAWAN PADA ZULINDO TOUR \& TRAVEL SERVICE
}

\author{
rona tanjung ${ }^{1)}$, muhammad zulhardi ${ }^{2)}$ \\ ${ }^{1}$ Prodi Manajemen, Fakultas Ekonomi, Universitas Riau Kepulauan \\ ronatanjung07@gmail.com \\ ${ }^{2}$ Prodi Manajemen, Fakultas Ekonomi, Universitas Riau Kepulauan \\ zulhardi.muhammad@gmail.com
}

\begin{abstract}
The purpose of this study was to determine the effect of leadership style, work discipline and work compensation on employee performance on ZULINDO Tour and Travel Service. This type of research is quantitative descriptive with data collection techniques using questionnaires. The population of this study was 47 people with 47 employees. The sampling technique uses random sampling. The results of hypothesis testing for leadership style variables (X1) show the results of $t$ count $4.826>t$ table 2.016 and a significant value of $0.000<0.05$ so that the decisions taken are Ho rejected and $\mathrm{Ha}$ accepted. This means that the Leadership Style has a significant effect on Employee Performance. Hypothesis testing for work discipline variables (X2) shows the value of $t$ count $4.136>t$ table 2.016 and significant value $0,000<0.05$ so that the decision taken is Ho rejected and Ha accepted. This means that Work Discipline significantly influences Employee Performance. Testing the hypothesis of work compensation variable (X3) value of $t$ count $3.265>t$ table 2.016 and significant value $0.002<0.05$ so that the decision taken is Ho rejected and Ha accepted. This means that Work Compensation has a significant effect on Employee Performance. The result of $F$ test shows that the $F$ value is 47.320 (F count) $>2.82$ ( F table) and the significance value is $0.000<0.05$ so that the decision taken is Ho rejected and Ha accepted. These results indicate that the variable Leadership Style (X1), Work Discipline (X2), and Work Compensation (X3) simultaneously have a significant effect on the Employee Performance variable (Y).
\end{abstract}

Keywords: Leadership Style, Work Discipline, Work Compensation, Employee Performance

\begin{abstract}
ABSTRAK
Tujuan penelitian ini untuk mengetahui pengaruh gaya kepemimpinan, disiplin kerja dan kompensasi kerja terhadap kinerja karyawan pada ZULINDO Tour and Travel Service. Jenis penelitian ini adalah deskriptif kuantitatif dengan teknik pengumpulan data mengunakan kuesioner. Populasi penelitian ini 47 orang dengan sempel 47 orang karyawan. Teknik samplingnya mengunakan sampling random. Hasil pengujian hipotesis untuk variabel gaya kepemimpinan (X1) menujukkan hasil t hitung 4,826 > t tabel 2,016 dan nilai signifikan $0,000<0,05$ sehingga keputusan yang diambil adalah Ho ditolak dan Ha diterima. Hal ini berarti Gaya Kepemimpinan berpengaruh signifikan terhadap Kinerja Karyawan. Pengujian hipotesis untuk variabel disiplin kerja (X2) menunjukkan nilai t hitung 4,136 > t tabel 2,016 dan nilai signifikan 0,000 <0,05 sehingga keputusan yang diambil adalah Ho ditolak dan Ha diterima. Hal ini berarti bahwa Disiplin Kerja berpengaruh secara signifikan terhadap Kinerja Karyawan. Pengujian hipotesis variabel kompensasi kerj (X3) nilai t hitung 3,265 > t tabel 2,016 dan nilai signifikan 0,002 <
\end{abstract}


0,05 sehingga keputusan yang diambil adalah Ho ditolak dan Ha diterima. Hal ini berarti bahwa Kompensasi Kerja berpengaruh secara signifikan terhadap Kinerja Karyawan. Hasil uji F sebesar memperlihatkan nilai F sebesar 47,320 (F hitung) $>2,82$ (F tabel) dan nilai signifikansi sebesar 0,000 $<0,05$ sehingga keputusan yang diambil adalah Ho ditolak dan Ha diterima. Hasil ini menunjukkan bahwa variabel Gaya Kepemimpinan (X1), Disiplin Kerja (X2), dan Kompensasi Kerja (X3) secara simultan berpengaruh signifikan terhadap variabel Kinerja Karyawan (Y).

Kata Kunci : Gaya Kepemimpinan, Disiplin Kerja, Kompensasi Kerja, Kinerja Karyawan 


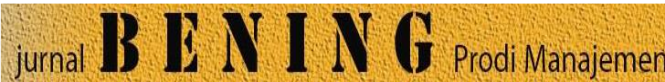
UNIVERSITAS RIAU KEPULAUAN BATAM

\section{PENDAHULUAN}

Setiap organisasai memerlukan manajemen yang berkaitan dengan upaya-upaya untuk meningkatkan efektifitas organisasi dan pencapaian tujuan perusahaan. Tujuan perusahaan akan dapat dicapai melalui kinerja yang positif dari karyawannya, sebaliknya organisasi akan menghadapi hambatan dalam pencapaian tujuan manakala kinerja para karyawan tidak efektif, dalam arti tidak dapat memenuhi tuntutan pekerjaan yang dinginkan oleh organisasi. Bagi pimpinan organisasi, kinerja karyawan menjadi sangat penting karena kinerja merupakan tolak ukur bagi keberhasilan dalam mengelola organisasi yang dipimpinnya. Jadi, kinerja merupakan faktor sentral bagi pekerjaan manajemen dalam mengelola organisasi, karena itu adalah penting bagi manajemen untuk mengenali dan memahami berbagai aspek yang berkaitan dengan kinerja karyawan baik dari faktor penyebabnya maupun dari segi faktor akibatnya.

Pendefinisian kinerja mengacu pada hasil kerja yang dicapai oleh orang atau kelompok orang dalam suatu organisasi berdasarkan satuan waktu atau ukuran tertentu. Pemahaman seperti ini mengandung penafsiran yang luas, terutama dalam segi pendekatan dan ruang lingkup kajiannya serta penggunaan kriteria atau indikator untuk menentukan presentasi atau penampilan kerja. Pendefinisian kinerja yang mengacu pada pencapaian hasil kerja, dari segi pendekatan dan ruang lingkup kajiannya dimungkinkan dapat dilakukan dari aspek individual atau organisasional.
Seharusnya karyawan perlu memiliki kinerja tinggi, sebab kinerja tinggi yang dimiliki karyawan dapat meningkatkan perkembangan perusahaan dan meningkatkan kerja bagi karyawan secara optimal, agar dapat bertahan di perusahaan. Akan tetapi pada kenyataannya tidak semua karyawan memiliki kinerja tinggi. Hal tersebut juga terjadi di perusahaan Zulindo Tour and Travel Service, Rendahnya kinerja karyawan dapat diketahui melalui hasil observasi mengenai perilaku karyawan dilihat dari intensitas waktu kerja, hanya sebagian karyawan yang terlihat memiliki kinerja tinggi. Karyawan sering melanggar waktu jam istirahat lebih lama dari ketentuan waktu peraturan perusahaan, sebagian karyawan terlambat masuk kerja. Sebagian karyawan kurang bertanggung jawab atas pekerjaan yang dilakukan. Hal ini terlihat saat observasi, masih ada beberapa karyawan saat bekerja lebih suka berbicara dengan teman kerja, sehingga hasil kerja tidak dapat maksimal. Selain itu, sikap kebersamaan dalam bekerja pada karyawan masih kurang. Kurang kebersamaan dalam bekerja terlihat masing-masing karyawan dalam bekerja bersifat individual yang tidak disiplin dan mental bertanggung jawab kerja rendah. Perilaku tidak disiplin pada karyawan merupakan salah satu faktor yang mempengaruhi kinerja karyawan.

Menurut Terry dalam Sutrisno (2011:87) bahwa disiplin merupakan alat penggerak karyawan agar tiap pekerjaan dapat berjalan dengan lancar, maka harus diusahakan agar ada disiplin yang baik. Dengan adanya disiplin kerja pada masing-masing karyawan maka dapat meningkatkan kinerja dan 
mencapai tujuan perusahaan. Patuh terhadap aturan-aturan yang telah ditetapkan perusahaan adalah wujud nyata dari rasa tanggung jawab karyawan tehadap pekerjaan yang diberikan. Apabila karyawan menerapkan disiplin kerja pada dirinya maka akan mendapatkan penghargaan bahkan kompensasi atas cerminan perilaku yang patuh, taat, dan baik. Adapun jenis-jenis disiplin kerja yaitu sebagai berikut : (1) Disiplin Preventif, (2) Disiplin Korektif, dan (3) Disiplin Progresif.

Kedisiplinan karyawan dalam bekerja juga dapat berpengaruh terhadap kinerja karyawan. Seorang karyawan yang mempunyai tingkat kedisiplinan yang tinggi akan tetap bekerja dengan baik walaupun tanpa diawasi oleh atasan. Seorang karyawan yang tidak disiplin akan mencuri waktu kerja untuk melakukan hal-hal lain yang tidak ada kaitannya dengan pekerjaan. Demikian juga karyawan yang mempunyai kedisiplinan yang tinggi akan mentaati peraturan yang ada dalam lingkungan kerja dengan kesadaran yang tinggi tanpa ada rasa paksaan. Sehingga karyawan yang mempunyai kedisiplinan kerja yang tinggi akan mempunyai kinerja yang baik karena waktu kerja dimanfaatkan sebaik mungkin untuk melaksanakan pekerjaan sesuai dengan target yang telah tetapkan.

Pemimpin dalam kegiatannya memiliki berbagai gaya, gaya kepemimpinan dalam organisasi juga memegang peranan yang sangat penting bagi pencapaian tujuan organisasi. Pemberian kompensasi kepada karyawan seharusnya mendapat perhatian yang utama dari pimpinan, karena dengan gaji atau upah yang cukup dan memadai akan membawa pengaruh positif terhadap semangat kerja dan kinerja karyawan dibanding dengan sumbangan tenaga maupun keahlian yang diberikan oleh perusahaan. Dengan demikian, diharapkan tujuan perusahaan tersebut bisa tercapai dengan baik. Perusahaan dalam memberikan kompensasi kepada karyawan perlu memperhatikan kemampuan karyawan.

Selain gaya kepemimpinan, ada hal lain yang telah diamati sebelumnya yakni mengenai kompensasi. Masih ada beberapa karyawan yang belum mendapatkan kompensasi sesuai yang diharapkan. Hal tersebut memang menjadi kebijakan perusahaan yang tentunya ada alasan dibalik pemberlakuan kebijakan pemberian kompensasi terhadap karyawan tersebut. Namun tak bisa kita pungkiri bahwa kompensasi dapat berpengaruh terhadap apa yang dilakukan karyawan ditempat kerjanya. Ketidakpuasan terhadap kompensasi tentu dapat memicu kinerja karyawan tersebut dapat melemah, begitu pun sebaliknya. Selain gaya kepemimpinan dan kompensasi, peneliti juga mengamati mengenai komitmen organisasi. Dalam hal ini, komitmen dapat berpengaruh terhadap kinerja karyawan. Beberapa penelitian menunjukkan bahwa komitmen organisasi berguna sebagai alat untuk melihat beberapa prilaku yang sangat penting, seperti : kinerja, kehadiran ditempat kerja dan keluar masuknya karyawan dari organisasi. Kompensasi merupakan salah satu fungsi yang penting dalam manajemen sumber daya manusia (MSDM). Karena kompensasi merupakan salah satu aspek yang paling sensitif di dalam hubungan kerja. Kasus yang terjadi dalam hubungan kerja mengandung 
masalah kompensasi dan berbagai segi yang terkait, seperti tunjangan, kenaikan kompensasi, struktur kompensasi dan skala kompensasi.

Kompensasi meliputi bentuk pembayaran tunai langsung, pembayaran tidak langsung dalam bentuk manfaat karyawan, dan insentif untuk memotivasi karyawan agar bekerja keras untuk mencapai produktivitas yang semakin tinggi. Jika dikelola dengan baik, maka dengan kompensasi ini dapat membantu perusahaan untuk mencapai produktivitas yang semakin tinggi bagi karyawannya. Sebaliknya jika tanpa kompensasi yang cukup, maka karyawan akan sangat mungkin untuk mereka dapat meninggalkan perusahaan dan untuk melakukan penempatan kembali sangatlah tidak mudah.

Kinerja berasal dari kata job performance atau actual performance yang berarti prestasi kerja atau prestasi sesungguhnya yang dicapai oleh seseorang. Pengertian kinerja adalah hasil kerja secara kualitas dan kuantitas yang dicapai oleh seorang pegawai dalam melaksanakan tugasnya sesuai dengan tanggung jawab yang diberikan kepadanya (Mangkunegara, 2015:67)

\section{HIPOTESIS PENELITIAN}

H1 : Diduga gaya kepemimpinan (X1) berpengaruh secara langsung dan signifikan dengan kinerja karyawan (Y) Zulindo Tour and Travel Service.

$\mathrm{H} 2$ : Diduga disiplin kerja (X2) berpengaruh secara langsung dan signifikan dengan kinerja karyawan (Y) Zulindo Tour and Travel Service.
H3 : Diduga kompensasi kerja (X3) berpengaruh secara langsung dan signifikan dengan kinerja karyawan (Y) Zulindo Tour and Travel Service.

H4 : Diduga gaya kepemimpinan (X1), disiplin kerja (X2) dan kompensasi kerja berpengaruh secara langsung bersama terhadap kinerja karyawan (Y) Zulindo Tour and Travel Service.

\section{METODE PENELITIAN}

\section{Teknik Pengambilan Sampel}

Populasi menurut sugiyono (2015) populasi adalah wilayah generalisasi yang terdiri atas obyek atau subyek yang mempunyai kuantitas dan karakteristik tertentu yang ditetapkan oleh peneliti untuk dipelajari dan kemudian ditarik kesimpulannya. Jadi populasi bukan hanya orang, tetapi juga objek dan benda-benda alam yang lain. Populasi juga bukan hanya sekedar jumlah yang hanya pada objek subjek yang dipelajari, tetapi meliputi karakteristik atau sifat yang dimiliki oleh subjek atau objek. Penelitian ini yang menjadi populasinya adalah karyawan Zulindo Tour and Travel Service yang berjumlah 47 karyawan.

Arikunto (2010:104) jika jumlah populasinya kurang dari 100 orang, maka jumlah sampelnya diambil secara keseluruhan, tetapi jika populasinya lebih besar dari 100 orang, maka bisa diambil 10-15\% atau 20-25\% dari jumlah populasinya. Dimana dalam penelitian ini populasinya sebanyak 47 karyawan yang bekerja di perusahaan terkait. Maka untuk sampelnya sendiri akan diambil 
jurnad B E N I N G Prodi inanjemen UNIVERSITAS RIAU KEPULAUAN BATAM

secara keseluruhan dari jumlah populasi yang ada.

\section{Jenis data}

Data yang digunakan dalam penelitian ini meliputi:

a. Data Primer, Data primer adalah data yang diperoleh peneliti secara langsung dari sumbernya. Biasanya untuk dapat memperoleh data primer atas objek yang akan diteliti maka peneliti biasanya melakukan dengan cara wawancara dengan para pihak-pihak yang terlibat dengan masalah terkait, dengan menyebarkan kuisioner kepada karyawan, mengadakan penelitian serta dengan melakukan pencatatan secara langsung terhadap objek penelitian atau mencatat fakta-fakta yang ada diperusahaan. Penelitian ini data primer diperoleh dari kuesioner yang diberikan kepada responden yang berhubungan dengan variabel gaya kepemimpinan, disiplin kerja, kompensasi kerja dan kinerja karyawan.

b. Data Sekunder, Data sekunder merupakan data yang penulis peroleh secara tidak langsung melalui perantara diperoleh dan dicatat oleh pihak lain Supomo (2012). Data ini dapat diperoleh melalui literature, jurnal, dan sumbersumber pendukung penelitian lainnya. Data sekunder yang dimaksud dalam penelitian ini data-data yang dapat bersumber dari buku-buku, artikel, jurnal, skripsi, tesis, situs internet sumber bacaan lain yang ada kaitannya dengan pembahasan skripsi ini juga berasal dari data-data perusahaan yang relevan dengan pembahasan penelitian yang dimaksud. Data sekunder yang diperoleh adalah dokumen berupa profil perusahaan yang terdiri atas visi,misi dan struktur organisasi perusahaan serta data karyawan yang berkaitan dengan penelitian ini.

\section{Teknik Pengumpulan Data}

Dalam penelitian ini data yang akan dikumpulkan berupa data primer dan data sekunder, maka peneliti akan menggunakan alat pengumpulan data berupa:

a. Kuesioner merupakan Teknik pengumpulan data dengan kuesioner merupakan satu teknik pengumpulan data yang memberikan daftar pertanyaan kepada responden, dengan harapan responden akan memberikan respon terhadap pertanyaan yang ada dalam kuesioner.

b. Wawancara merupakan Teknik pengumpulan data dengan wawancara merupaka teknik pengumpulan data dengan menggunakan pertanyaan lisan kepada subyek penelitian..

Studi pustaka merupakan metode pengumpulan data yang dilakukan dengan membaca buku-buku, literature, jurnal-jurnal, referensi yang berkaitan dengan penelitian yang sedang dilakukan.

c. Dokumentasi adalah sebuah teknik pengumpulan data 
yang dilakukan seorang peneliti yang tidak secara langsung ditujukan pada subyek penelitian, namun melalui dokumen. Dokumen yang dapat digunakan beragam jenisnya, dapat berupa buku harian atau catatan, laporan dan dokumen lainnya..

\section{HASIL PENELITIAN}

\section{Uji Validitas}

\begin{tabular}{|c|c|c|c|c|}
\hline Variabel & Item & r Hitung & r Tabel & $\begin{array}{c}\text { Keteran } \\
\text { gan }\end{array}$ \\
\hline \multirow{8}{*}{$\begin{array}{c}\text { Gaya } \\
\text { Kepemim } \\
\text { pinan }\end{array}$} & $\mathrm{X} 1.1$ & 0,596 & 0,288 & Valid \\
\hline & X1. 2 & 0,792 & 0,288 & Valid \\
\hline & X1. 3 & 0,700 & 0,288 & Valid \\
\hline & X1. 4 & 0,624 & 0,288 & Valid \\
\hline & $\mathrm{X} 1.5$ & 0,792 & 0,288 & Valid \\
\hline & X1.6 & 0,684 & 0,288 & Valid \\
\hline & $\mathrm{X} 1.7$ & 0,307 & 0,288 & Valid \\
\hline & $\mathrm{X} 1.8$ & 0,747 & 0,288 & Valid \\
\hline \multirow{6}{*}{$\begin{array}{c}\text { Disiplin } \\
\text { Kerja }\end{array}$} & $\mathrm{X} 2.1$ & 0,794 & 0,288 & Valid \\
\hline & $\mathrm{X} 2.2$ & 0,594 & 0,288 & Valid \\
\hline & $\mathrm{X} 2.3$ & 0,620 & 0,288 & Valid \\
\hline & $\mathrm{X} 2.4$ & 0,628 & 0,288 & Valid \\
\hline & $\mathrm{X} 2.5$ & 0,433 & 0,288 & Valid \\
\hline & $\mathrm{X} 2.6$ & 0,443 & 0,288 & Valid \\
\hline \multirow{4}{*}{$\begin{array}{c}\text { Kompens } \\
\text { asi }\end{array}$} & X3. 1 & 0,646 & 0,288 & Valid \\
\hline & X3. 2 & 0,902 & 0,288 & Valid \\
\hline & X3. 3 & 0,638 & 0,288 & Valid \\
\hline & X3. 4 & 0,902 & 0,288 & Valid \\
\hline \multirow{10}{*}{$\begin{array}{c}\text { Kinererja } \\
\text { Karyawa } \\
n\end{array}$} & Y. 1 & 0,485 & 0,288 & Valid \\
\hline & Y. 2 & 0,720 & 0,288 & Valid \\
\hline & Y. 3 & 0,742 & 0,288 & Valid \\
\hline & Y. 4 & 0,342 & 0,288 & Valid \\
\hline & Y. 5 & 0,316 & 0,288 & Valid \\
\hline & Y. 6 & 0,731 & 0,288 & Valid \\
\hline & Y. 7 & 0.606 & 0,288 & Valid \\
\hline & Y. 8 & 0,615 & 0,288 & Valid \\
\hline & Y.9 & 0,477 & 0,288 & Valid \\
\hline & Y. 10 & 0,565 & 0,288 & Valid \\
\hline
\end{tabular}

menunjukkan bahwa semua butir pernyataan mempunyai nilai $r$ hitung $>\mathrm{r}$ tabel, dengan taraf signifikan $\alpha=$ 0,05 dan nilai $r$ tabel nya sebesar 0,288 dapat disimpulkan bahwa semua pernyataan pada variabel $X 1$, $\mathrm{X} 2$, X3, dan Y dinyatakan valid.

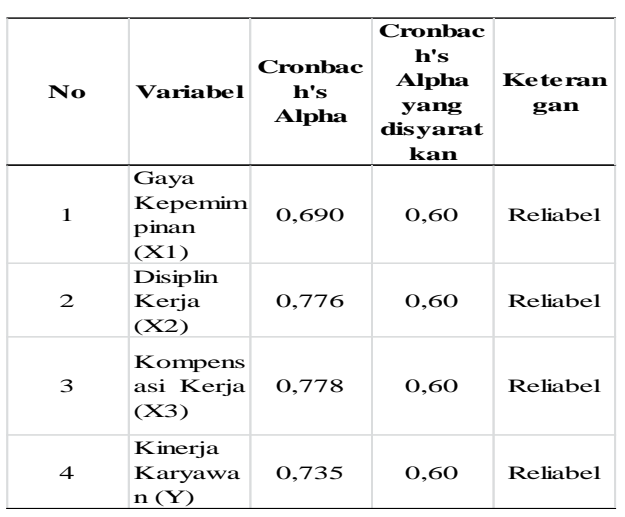

Dari tabel diatas dapat dilihat bahwa R Alpha dari masing - masing variabel $\mathrm{X} 1, \mathrm{X} 2, \mathrm{X} 3$ dan $\mathrm{Y}$ lebih besar dari 0,60. Dengan demikian dapat disimpulkan bahwa data yang diuji tersebut dinyatakan reliabel.

\section{Uji Normalitas}

\section{One-Sample Kolmogorov- Smirnov Test}

\begin{tabular}{|c|c|c|}
\hline & & $\begin{array}{c}\text { Unstandar } \\
\text { dized } \\
\text { Residual }\end{array}$ \\
\hline $\mathrm{N}$ & & 47 \\
\hline Normal & Mean & 0 \\
\hline Parameters $^{\mathrm{a}, \mathrm{b}}$ & $\begin{array}{l}\text { Std. } \\
\text { Deviation }\end{array}$ & 2.665533 \\
\hline & Absolute & 0.123 \\
\hline $\begin{array}{l}\text { Most Extreme } \\
\text { Differences }\end{array}$ & Positive & 0.057 \\
\hline & Negative & -0.123 \\
\hline Test Statistic & & 0.123 \\
\hline Asymp. Sig. (2- & ailed) & $.074^{c}$ \\
\hline a. Test distrib & is Nor & \\
\hline b. Calculated $f$ & data. & \\
\hline c. Lilliefors Sig & cance C & i \\
\hline
\end{tabular}

Berdasarkan hasil uji Kolmogorov-smirnov, diketahui nilai Asymp. Sig. (2-tailed) $0.074>0,05$ (alpha), maka dapat disimpulkan bahwa nilai residual berdistribusi normal..

\section{Uji Reliabilitas}



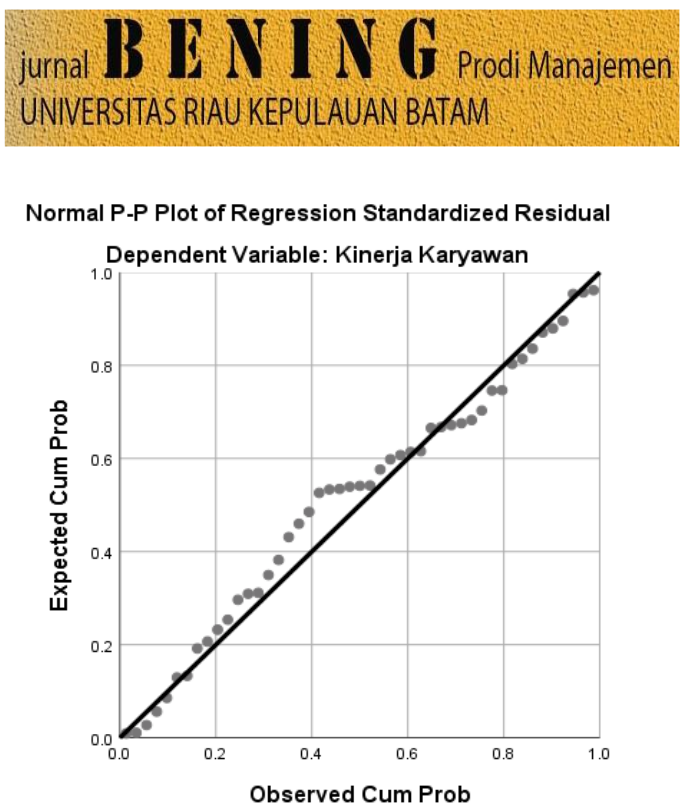

Gambar memperlihatkan ketentuan bahwa titik-titik data menyebar disekitar garis diagonal dan mengikuti arah garis diagonal maka dapat dikatakan data memenuhi asumsi normalitas.

\section{Uji Multikolonieritas}

\begin{tabular}{cccc}
\hline \multirow{2}{*}{ Model } & & \multicolumn{2}{c}{$\begin{array}{c}\text { Collinearity } \\
\text { Statistics }\end{array}$} \\
\cline { 3 - 4 } & & $\begin{array}{c}\text { Toleranc } \\
\text { e }\end{array}$ & VIF \\
\hline & $\begin{array}{l}\text { (Constant) } \\
\text { Gaya } \\
\text { Kepemimpi }\end{array}$ & 0.164 & 6.081 \\
& $\begin{array}{l}\text { nan } \\
\text { Disiplin } \\
\text { Kerja } \\
\text { Kompensa } \\
\text { si Kerja }\end{array}$ & 0.512 & 1.951 \\
\hline
\end{tabular}

Tabel menunjukkan bahwa nilai VIF untuk variabel $\mathrm{X} 1, \mathrm{X} 2$ dan X3 masing-masing sebesar 6,081; 1,951: dan 4,282 sehingga dapat disimpulkan bahwa dalam model regresi tidak terdapat gejala multikolinearitas antar variabel bebas karena nilai VIF lebih kecil dari 10 yang berarti bahwa variabel $\mathrm{X} 1, \mathrm{X} 2$ dan X3 dapat digunakan sebagai variabel yang saling independen.

\section{Uji Heteroskedastisitas}

Volume 5 No. 2 Tahun 2018

P-ISSN 2252-5262

E-ISSN 2614-499

\section{Coefficients $^{\mathrm{a}}$}

\begin{tabular}{rlll}
\hline Model & & $\mathrm{t}$ & Sig. \\
\hline & $\begin{array}{l}\text { (Constant) } \\
\text { Gaya }\end{array}$ & -0.502 & 0.618 \\
& $\begin{array}{l}\text { Kepemimpi } \\
\text { nan }\end{array}$ & 0.143 & 0.887 \\
& $\begin{array}{l}\text { Disiplin } \\
\text { Kerja } \\
\text { Kompensa } \\
\text { si Kerja }\end{array}$ & 0.643 & 0.524 \\
\hline a. Dependent Variable: RES2 & 0.624 \\
\hline
\end{tabular}

Hasil pengujian Glejser melihat nilai probabilitas dengan signifikansi > nilai alpha $(0,05)$ maka model tidak mengalami heteroskedastisitas. Pada Tabel diketahui bahwa nilai probabilitas atau signifikansi dari masing-masing variabel 0,$887 ; 0,524 ;$ dan 0,624 lebih besar dari nilai alpha $(0,05)$ maka dapat disimpulkan bahwa dalam model regresi tidak terdapat gejala heteroskedastisitas.

\section{PENGUJIAN HIPOTESIS}

\section{Uji t (Parsial)}

\begin{tabular}{|c|c|c|c|c|c|}
\hline \multicolumn{6}{|c|}{ Coefficients $^{a}$} \\
\hline \multirow{2}{*}{ Model } & & \multicolumn{2}{|c|}{$\begin{array}{c}\text { Unstandardized } \\
\text { Coefficients }\end{array}$} & \multirow{2}{*}{$t$} & \multirow{2}{*}{ Sig. } \\
\hline & & $\mathrm{B}$ & Std. Error & & \\
\hline \multirow{6}{*}{1} & $\begin{array}{l}\text { (Consta } \\
\text { nt) }\end{array}$ & 1.666 & 3.02 & 0.552 & 0.584 \\
\hline & Gaya & & & & \\
\hline & $\begin{array}{l}\text { Kepemi } \\
\text { mpinan }\end{array}$ & 1.112 & 0.229 & 4.862 & 0 \\
\hline & $\begin{array}{l}\text { Disiplin } \\
\text { Kerja }\end{array}$ & 0.592 & 0.143 & 4.136 & 0 \\
\hline & Kompe & & & & \\
\hline & $\begin{array}{l}\text { nsasi } \\
\text { Kerja }\end{array}$ & -0.822 & 0.252 & -3.265 & 0.002 \\
\hline
\end{tabular}

Hasil dari Tabel 4.12 menunjukkan bahwa variabel Gaya Kepemimpinan (X1) nilai t hitung $4,826>t$ tabel 2,016 dan nilai signifikan $0,000<0,05$ sehingga keputusan yang diambil adalah Ho ditolak dan $\mathrm{Ha}$ diterima. Hal ini 


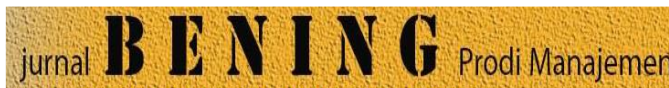
UNIVERSITAS RIAU KEPULAUAN BATAM

berarti Gaya Kepemimpinan berpengaruh signifikan terhadap Kinerja Karyawan.

\section{Variabel Disiplin}

Kerja (X2) menunjukkan nilai $t$ hitung 4,136>t tabel 2,016 dan nilai signifikan $0,000<0,05$ sehingga keputusan yang diambil adalah Ho ditolak dan Ha diterima. Hal ini berarti bahwa Disiplin Kerja berpengaruh secara signifikan terhadap Kinerja Karyawan.

Variabel Kompensasi Kerja (X3) nilai t hitung 3,265>t tabel 2,016 dan nilai signifikan $0,002<$ 0,05 sehingga keputusan yang diambil adalah Ho ditolak dan $\mathrm{Ha}$ diterima. Hal ini berarti bahwa Kompensasi Kerja berpengaruh secara signifikan terhadap Kinerja Karyawan.

\section{Uji F (Simultan)}

\begin{tabular}{rlrrrrr}
\multicolumn{6}{c}{ ANOVA $^{\mathrm{a}}$} \\
\hline Model & \multicolumn{1}{c}{$\begin{array}{c}\text { Sum of } \\
\text { Squares }\end{array}$} & df & $\begin{array}{c}\text { Mean } \\
\text { Square }\end{array}$ & F & Sig. \\
\hline \multirow{4}{*}{1} & $\begin{array}{l}\text { Regres } \\
\text { sion }\end{array}$ & 1079 & 3 & 359.67 & 47.32 & $.000^{\mathrm{b}}$ \\
& $\begin{array}{l}\text { Residu } \\
\text { al }\end{array}$ & 326.833 & 43 & 7.601 & & \\
& Total & 1405.83 & 46 & & & \\
\hline
\end{tabular}

a. Dependent Variable: Kinerja Karyawan

b. Predictors: (Constant), Kompensasi Kerja, Disiplin Kerja, Gaya Kepemimpinan

Hasil uji $\mathrm{F}$ memperlihatkan nilai $\mathrm{F}$ sebesar 47,320 (F hitung) > 2,82 (F tabel) dan nilai signifikansi sebesar $0,000<0,05$ sehingga keputusan yang diambil adalah Ho ditolak dan Ha diterima. Hasil ini menunjukkan bahwa variabel Gaya Kepemimpinan (X1), Disiplin Kerja (X2), dan Kompensasi Kerja (X3) secara simultan berpengaruh signifikan terhadap variabel Kinerja Karyawan (Y).

\section{Uji Koefisien Determinasi (R2)}

Volume 5 No. 2 Tahun 2018

P-ISSN 2252-5262

E-ISSN 2614-499

\begin{tabular}{l|llll} 
Model Summary & \\
\hline Model & R & R Square & $\begin{array}{c}\text { Adjusted R } \\
\text { Square }\end{array}$ & $\begin{array}{c}\text { Std. Error } \\
\text { of the } \\
\text { Estimate }\end{array}$ \\
\hline 1 & $.876^{\text {a }}$ & 0.768 & 0.751 & 2.757 \\
\hline $\begin{array}{l}\text { a. Predictors: (Constant), Kompensasi Kerja, Disiplin Kerja, } \\
\text { Gaya Kepemimpinan } \\
\text { b. Dependent Variable: Kinerja Karyawan }\end{array}$
\end{tabular}

Hasil Uji Koefisien Determinasi memperlihatkan nilai $\mathrm{R}$ Square sebesar 0,768, hal ini mengandung arti bahwa pengaruh Gaya Kepemimpinan, Disiplin Kerja, Kompensasi Kerja secara simultan terhadap Kinerja Karyawan adalah sebesar $76.8 \%$. sedangkan sisanya yaitu $23.2 \%$ dipengaruhi oleh variabel lainya yang tidak diteliti.

\section{KESIMPULAN}

Berdasarkan hasil penelitian dan pembahasan yang telah dilakukan pada bab sebelumnya, maka dapat disimpulkan bahwa:

1. Pengujian hipotesis untuk variabel Gaya Kepemimpinan (X1) menunjukan Gaya Kepemimpinan (X1) nilai $\mathrm{t}$ hitung 4,826 > t tabel 2,016 dan nilai signifikan $0,000<0,05$ sehingga keputusan yang diambil adalah $\mathrm{H}_{\mathrm{o}}$ ditolak dan $\mathrm{H}_{\mathrm{a}}$ diterima. Hal ini berarti Gaya Kepemimpinan berpengaruh signifikan terhadap Kinerja Karyawan.

2. Pengujian hipotesis untuk variabel Disiplin Kerja (X2) menunjukan nilai t hitung 4,136 $>\mathrm{t}$ tabel 2,016 dan nilai signifikan $0,000<0,05$ sehingga keputusan yang diambil adalah $\mathrm{H}_{\mathrm{o}}$ ditolak dan $\mathrm{H}_{\mathrm{a}}$ diterima. Hal ini berarti bahwa Disiplin Kerja berpengaruh secara signifikan terhadap Kinerja Karyawan. 


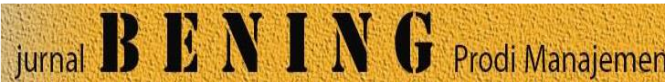
UNIVERSITAS RIAU KEPULAUAN BATAM

3. Pengujian hipotesis untuk variabel Kompensasi Kerja (X3) menunjukan nilai t hitung 3,265 $>\mathrm{t}$ tabel 2,016 dan nilai signifikan 0,002 <0,05 sehingga keputusan yang diambil adalah $\mathrm{H}_{\mathrm{o}}$ ditolak dan $\mathrm{H}_{\mathrm{a}}$ diterima. Hal ini berarti bahwa Kompensasi Kerja berpengaruh secara signifikan terhadap Kinerja Karyawan.

4. Hasil uji $\mathrm{F}$ memperlihatkan nilai F sebesar 47,320 (F hitung) > 2,82 (F tabel) dan nilai signifikansi sebesar $0,000<0,05$ sehingga keputusan yang diambil adalah $\mathrm{H}_{\mathrm{o}}$ ditolak dan $\mathrm{H}_{\mathrm{a}}$ diterima. Hasil ini menunjukkan bahwa variabel Gaya Kepemimpinan (X1), Disiplin Kerja (X2), dan Kompensasi Kerja (X3) secara simultan berpengaruh signifikan terhadap variabel Kinerja Karyawan (Y).

\section{SARAN}

Berdasarkan hasil penelitian ini, beberapa saran atau rekomendasi yang dapat diberikan kepada perusahaan maupun untuk penelitian yang akan datang sebagai berikut:

1. Karyawan diharapkan meningkatkan kembali disiplin kerja supaya kinerja karyawan dapat meningkat agar berdampak kepada kualitas dari zulindo tour and travel service.

2. Zulindo tour and travel service diharapkan menyesuaikan kompensasi agar karyawan makin semangat mengerjakan
Volume 5 No. 2 Tahun 2018

P-ISSN 2252-5262

E-ISSN 2614-499

kerjaan yang telah diberikan oleh perusahaan.

\section{DAFTAR PUSTAKA}

Anggraini, D. 2015. Pengaruh Gaya Kepemimpinan, Budaya Organisasi,

Komunikasi, Dan Lingkungan Kerja Terhadap Kinerja Karyawan Pada PT.

Cito Putra Utama Di Indrapasta Semarang. (Online) Semarang : Universitas Dian Nuswantoro: (http://eprints.dinus.ac.id) Diakses

November 2018.

Arikunto, Suharsimi. (2010). Prosedur Penelitian Suatu Pendekatan Praktik.

Jakarta: Rineka Cipta

Bangun, Wilson, (2014). Manajemen Sumber Daya Manusia. Jakarta: Erlangga.

Delti. 2015."Pengaruh

Kepemimpinan terhadap Kinerja Karyawan PT.TCM di Kubar". eJournal Ilmu Administrasi Bisnis. Volume 3, Nomor 2, http://ejournal.adbisni s.fisipunmul.ac.id/site/wpco ntent/uploads/2015/07/JU RNAL

Dessler, Gary, 2016. Human Resource Manamgement. New jersey: Pearson Education

Dharma, Surya. 2013. Manajemen Kinerja : Falsafah Teori dan Penerapannya. 


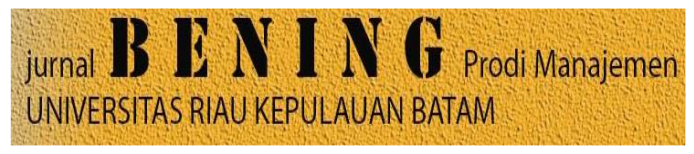

Yogyakarta: Pustaka Pelajar.

Frengky Basna. 2016, Analisis Gaya Kepemimpinan,

Kepuasan Kerja,

Komitmen

Organisasi dan

Kompetensi Terhadap

Kinerja Pegawai Badan

Pendapatan Daerah

Manado. Jurnal Riset

Bisnis dan Manajemen

Vol. 4, No.3, 319-334.

Handoko, T. Hani. 2012. Manajemen

Personalia dan Sumber

Daya Manusia.

Yogyakarta: BPFE.

-------------------. 2014. Manajemen

Personalia dan Sumber

Daya Manusia. BPFE-

Yogyakarta.

Yogyakarta.

Hasibuan, Malayu S.P. 2016.

Manajemen Sumber Daya

Manusia. Edisi Revisi.

Jakarta: Penerbit PT

Bumi Aksara.

2017,

Manajemen: Dasar,

Pengertian, dan Masalah.

Edisi Revisi.

Jakarta.

Mangkunegara, Anwar Prabu.

(2015). Manajemen

Sumber Daya Manusia

Perusahaan. Bandung:

PT Remaja Rosda Karya.

Sumber Daya Manusia

Perusahaan. Cetakan

kedua belas. Remaja

Rosdakarya:Bandung.

Marwansyah. 2016. Manajemen

Sumber Daya Manusia.

Edisi Dua. Cetakan

keempat. Bandung:

Alfabeta,CV
Volume 5 No. 2 Tahun 2018

P-ISSN 2252-5262

E-ISSN 2614-499

Rivai, Veithzal. (2013). Manajemen Sumber Daya Manusia Untuk Perusahaan

Dari Teori Ke Praktek.

Bandung: PT

Rajagrafindo Persada.

----------------.. 2014. Manajemen

Sumber Daya Manusia untuk Perusahaan, Edisi ke 6, PT. Raja Grafindo Persada, Depok, 16956

Rivai, Veithzal dan Ella Jauvani. 2013. Manajemen

Sumber Daya Manusia untuk Perusahaan :

Dari Teori ke Praktik.

Edisi Kedua. Cetakan

Kelima. PT. Raja

grafindo Persada. Jakarta.

2012. Manajemen

Sumber Daya Manusia

Untuk Perusahaan :

Dari Perusahaan Ke

Praktik, Edisi ke-1,

Rajawali Pers, Jakarta.

Siregar, Syofian. (2013). Metode Penelitian Kuantitatif. Jakarta: PT Fajar

Interpratama Mandiri

Sofyandi, Herman. 2011. Manajemen Sumber Daya Manusia. Graha Ilmu:

Yogyakarta.

Sugiyono (2015). Metode Penelitian Kombinasi

(Mix

Methods). Bandung:

Alfabeta.

(2016). Metode Penelitian Kuantitatif, Kualitatif, dan R\&D. Bandung:

Alfabeta

Sutikno, Sobry. (2014). Pemimpin dan Kepemimpinan Tips Praktis untuk Menjadi

Pemimpin yang Diidolakan. Lombok: Holistica. 
Sutrisno, edy, 2014. Manajemen

Sumber Daya Manusia.

Cetak Ke Enam. Pranada

Media Group, Jakarta.

2010. Manajemen

Sumber Daya Manusia.

Edisi Pertama. Cetakan

Pertama. Jakarta :

Penerbit Kencana.

Thoha, Miftah 2013. Kepemimpinan

Dalam Manajemen. Edisi

1, PT. Raja Grafindo, Jakarta. 